Supporting Information for ES\&T manuscript es0609710:

\title{
Perfluorooctanesulfonate and Perfluorooctanoate in Red Panda and Giant Panda from China
}

Authors: Jiayin Dai, Ming Li, Yihe Jin, Norimitsu Saito, Muqi Xu, Fuwen Wei

(Page 4,Table 2, Figure 2)

List of tables

Table S1. Mean, standard deviation, median, minimum, and maximum perfluorochemical concentrations $(\mu \mathrm{g} / \mathrm{L})$ in sera of pandas from different cities Table S2. An optimized analytical method for PFOS and PFOA using LC/MS

List of figures

Figure S1. The standard curve of PFOS

Figure S2. The LC/MS chromatogram of PFOS and PFOA in a deionized water (Concentration is $0.1 \mu \mathrm{g} / \mathrm{L}$, injection volume $10 \mu \mathrm{L}$ ) 
Table S1 Mean, standard deviation, median, minimum, and maximum perfluorochemical concentrations $(\mu \mathrm{g} / \mathrm{L})$ in sera of pandas from different cities

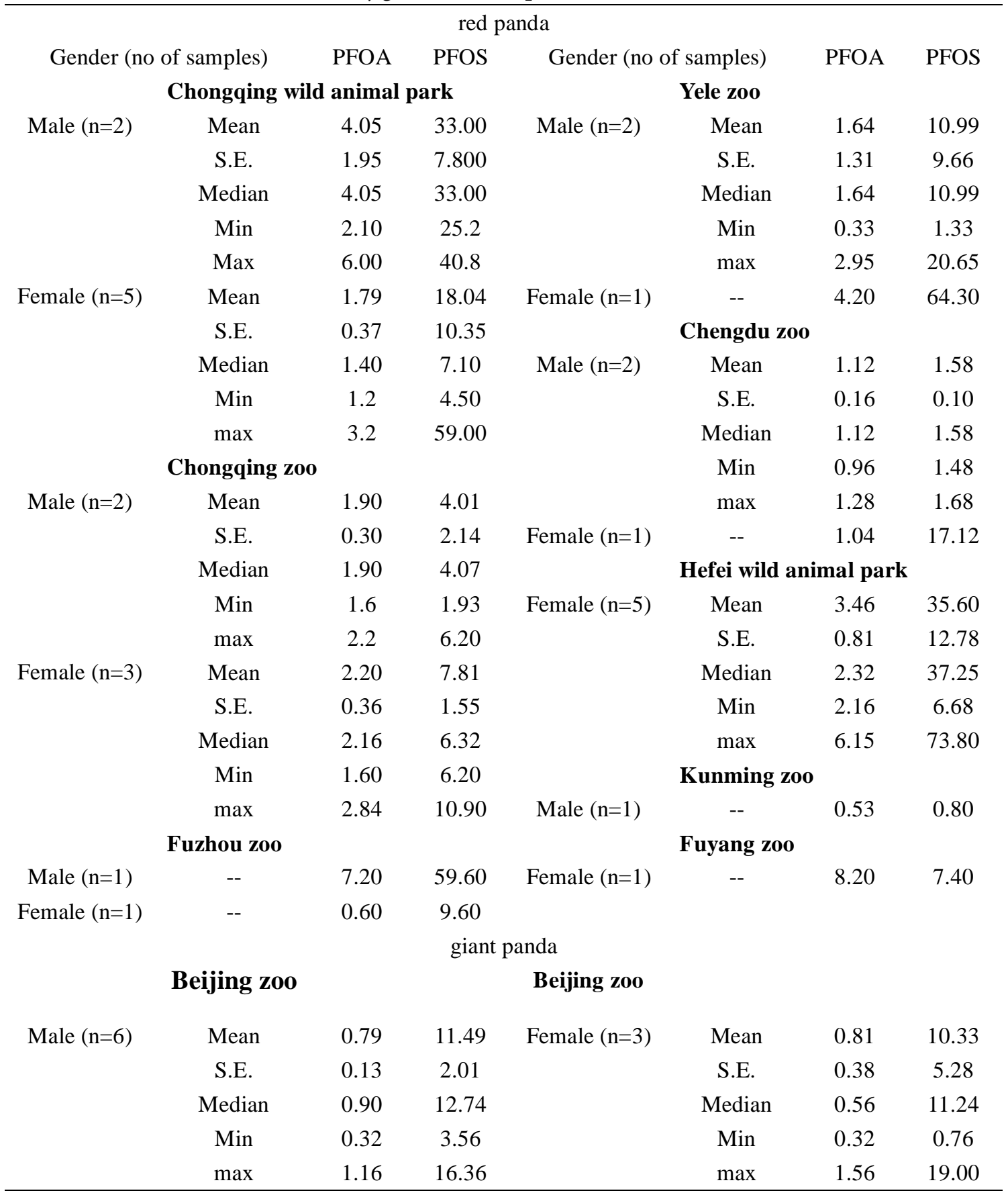


Table S2 An optimized analytical method for PFOS and PFOA using LC/MS

\begin{tabular}{|c|c|c|c|}
\hline HPLC & & MS & Agilent 1100MSD SL \\
\hline \multirow[t]{2}{*}{ Instrument } & Agilent 1100 & Instrument & ESI \\
\hline & Zorbax XDB C-18 & & \\
\hline Column & $(2.1 \times 150 \mathrm{~mm})$ & Ionization & $\mathrm{N}_{2}(50 \mathrm{psi})$ \\
\hline \multirow[t]{7}{*}{ Mobile phase $^{1)}$} & $\mathrm{A}: \mathrm{CH}_{3} \mathrm{CN}$ & Nebulizer & $\mathrm{N}_{2}(10.0 \mathrm{~L} / \mathrm{min}, 350\llcorner)$ \\
\hline & $\mathrm{B}: 10 \mathrm{mM}$ & & \\
\hline & $\mathrm{CH}_{3} \mathrm{COONH}_{4} / \mathrm{H}_{2} \mathrm{O}$ & Drying gas & Negative \\
\hline & $35\llcorner\llcorner$-(linear gradient & & \\
\hline & $2 \% \mathrm{~A} / \min )-45 \% \mathrm{~A}$ & Polarity & 100V (PFOA), 200V (PFOS) \\
\hline & & Fragmentor & $4000 \mathrm{~V}$ \\
\hline & & & Q1: 499, Q2: 500, Q3: 99 \\
\hline Flow rate & $0.2 \mathrm{~mL} / \mathrm{min}$ & Vcap & (PFOS) \\
\hline Oven temp & 40\llcorner & $\operatorname{SIM}(\mathrm{m} / \mathrm{z})$ & Q1: 413, Q2: 369 (PFOA) \\
\hline Injection volume & $10.0 \mu \mathrm{L}$ & & \\
\hline
\end{tabular}


Six point standard curves were prepared, and deionized water only was used after passing through a Presep-C Agri cartridge (Solid phase: Styrenedivinylbenzene polymethacylate on a polyethyelene hosing) (Presep-C, $220 \mathrm{mg}$ cartridge: Wako Pure Chemicals, Osaka Japan) to remove residual PFOS throughout this experiment. Standards for PFOS (98\%) and PFOA (96\%) were purchased from Fluka. The standard curve of PFOS is shown in Figure S1.

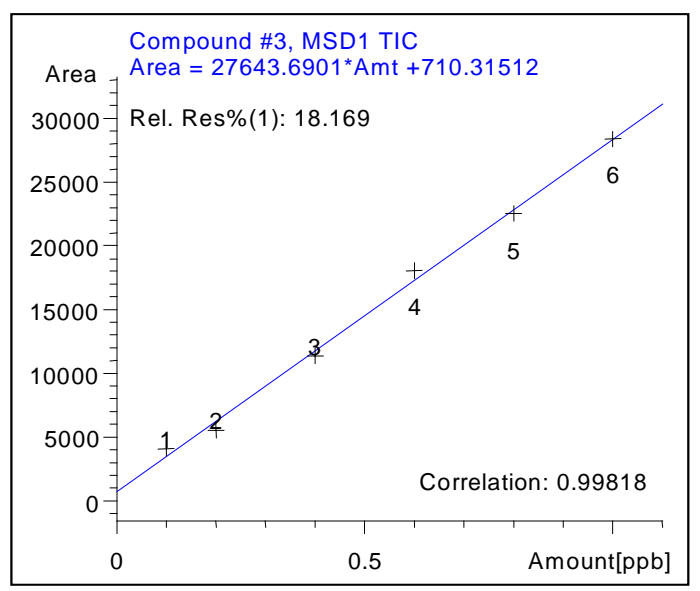

Concentration of PFOS (ug/L)

Figure S1 The standard curve of PFOS

The LC/MS chromatogram of PFOS and PFOA in a deionized water analyzed with LC/MS with an S/N ratio of 5.7 for PFOA, 10.1 for PFOS is shown in Figure S2, respectively.

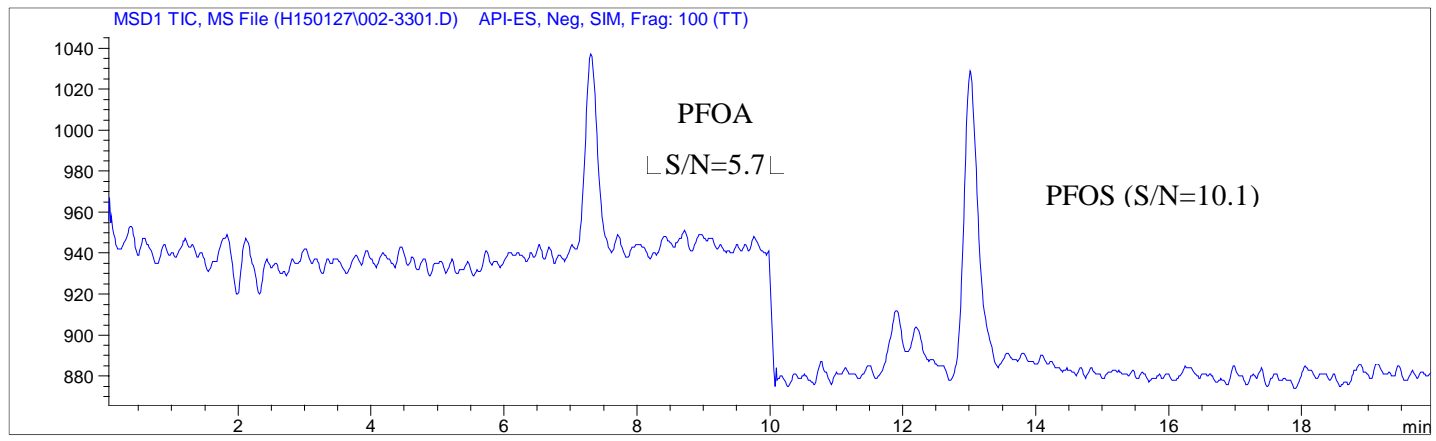

Figure S2 The LC/MS chromatogram of PFOS and PFOA in a deionized water

(Concentration is $0.1 \mu \mathrm{g} / \mathrm{L}$, injection volume $10 \mu \mathrm{L}$ ) 